\title{
EL METATEATRO EN LOS ENTREMESES DE JOSÉ JULIÁN LÓPEZ DE CASTRO
}

\author{
Federico Briante \\ Universidad de Sevilla \\ Sevilla, España \\ fbriante@us.es
}

RESUMEN / ABSTRACT

Partiendo de la idea consabida de que el teatro breve constituye un terreno harto propicio para la metateatralidad, en este artículo buscamos analizar los rasgos metateatrales presentes en los entremeses que escribió José Julián López de Castro, poeta y dramaturgo español setecentista. La elección de este objeto de estudio responde al escaso interés que la crítica literaria ha prestado, por un lado, a la vida y obra de este escritor madrileño y, por otro, al fenómeno de la metateatralidad en las piezas dramáticas breves del siglo XVIII español.

Palabras clave: José Julián López de Castro, siglo XVIII, metateatro, teatro en el teatro, teatro sobre el teatro.

\section{THE METATHEATRE IN THE INTERLUDES (ENTREMESES) OF JOSÉ JULIÁN LÓPEZ DE CASTRO}

Starting from the well-known idea that short theatre is a very favorable terrain for metatheatricality, in this work we seek to study the meta-theatrical features present in the interludes (entremeses) written by José Julián López de Castro, a Spanish poet and dramatist in the eighteenth-century. The choice of this object of study responds to the low interest that critics have given, on the one hand, to the life and work of this Madrid writer and, on the other, to the subject of meta-theatricality in the short dramatic pieces of the eighteenth-century Spanish.

KEYWORDS: José Julián López de Castro, eighteenth-century, meta-theatre, theatre within theatre, theatre about theatre. 


\section{INTRODUCCIÓN}

El teatro español de los Siglos de Oro ha despertado entre los estudiosos de la literatura un interés inmensamente mayor que el del siglo XVIII. Prueba de ello es el tema que aquí nos ocupa: la presencia de la metateatralidad en las obras dramáticas breves; a este respecto, abundan los estudiosos -Alfredo Hermenegildo (2001), Brioso Santos (2003), Pérez de León (2004), Graciela Balestrino (2011) o Hernández Martín (2016)- que se han interesado por autores como Cervantes, Calderón de la Barca o Agustín de Rojas Villandrando, entre otros $^{1}$; en cambio, no ocurre lo mismo con los dramaturgos dieciochescos, razón por la que hemos elegido a uno de ellos como objeto de nuestro trabajo; nos referimos al madrileño José Julián López de Castro. Al tratarse de un escritor prácticamente ignorado, consideramos conveniente empezar dando unos breves trazos sobre su biografía y producción literaria.

\section{JOSÉ JULIÁN LÓPEZ DE CASTRO. VIDA Y OBRA²}

Lo que hoy sabemos, más bien poco, de José Julián López de Castro se debe fundamentalmente a los estudios de Álvarez de Baena (77-80) y Barrera y Leirado (221). Ya en el siglo XX, Igartúa Landecho (1991) le dedica una tesis doctoral que valoramos enormemente por ser -hasta donde llega nuestro conocimiento- el único trabajo monográfico del que se dispone hoy día sobre este escritor. No obstante, dicho trabajo no ha logrado suscitar el interés de los investigadores por las numerosas vías de estudio que se abren con la producción literaria de López de Castro y que aún quedan por recorrer ${ }^{3}$.

$\mathrm{El}$ autor que estudiamos pertenece a una importante familia de dramaturgos (pero, sobre todo, de actores) españoles, una saga que se había iniciado, en el

También abundan los trabajos sobre metateatralidad en el teatro mayor de los autores áureos, como los de Cubero Corpas (1997), Canonica (2003), Maestro (2004), María Teresa Julio (2007) o Sáez Raposo (2011).

2 Para esta introducción se retoman los datos que ya publicamos en otro trabajo anterior nuestro sobre López de Castro; véase Federico Briante Benítez (2019).

Más allá de los estudiosos citados, no son muchos más los que se acuerdan en sus trabajos de José Julián López de Castro; véase Federico Briante Benítez (2019). 
siglo XVII, con Pedro de Castro 4 . José Julián nace en la capital de España el 16 de febrero de 1723. En un primer momento, desempeña las funciones de paje del vicario de Madrid y de notario apostólico en el obispado de Toledo; posteriormente, se dedicaría a la venta de libros en dos imprentas, sitas en las calles madrileñas de Jesús María y en la del Correo; además, tuvo un puesto de libros en la Puerta del Sol. En diciembre de 1753 contrae matrimonio con María de Fuente en la iglesia de San Juan. El 13 de marzo de 1762 muere de hidropesía en su ciudad natal.

López de Castro nos ha legado una producción literaria amplia, la mayor parte dentro de los géneros lírico y dramático, además de obras destinadas específicamente para el entretenimiento (como los piscatores). En el terreno de la lírica, conservamos de él algunas composiciones de temática religiosa (Villancicos espirituales al Nacimiento del Hijo de Dios; La bella hija de Madrid y blasón de la Merced; Nuevo prodigioso triunfo del glorioso San Francisco de Asís, etc.) o de carácter histórico-celebrativo (Elogios sobre el valor y nombre de los mayores capitanes que fueron esplendor de los siglos y Demostración gozosa de la más entrañable y fidelísima lealtad). Otros textos destacan por la vena festiva, chistosa -con ciertas dosis de sátira social, en ocasiones-que siempre acompañó al escritor madrileño y que se aprecia, por ejemplo, en la Relación satírica y curiosa que declara con el mayor donaire los casos, lances y chistes que pasan regularmente entre amas y criadas, pajes y mayordomos, cocheros y lacayos o en la Tarifa general. Regulación curiosa de lo que se necesita para mantener una casa en Madrid ${ }^{5}$.

Respecto a su quehacer en el género dramático, cabe señalar la comedia Más vale tarde que nunca, así como sus diez ${ }^{6}$ entremeses, cuyos títulos pasamos

$4 \quad$ Sobre esta saga, véase Martínez Rodríguez (105). El resto de datos biográficos sobre López de Castro pueden encontrarse en Álvarez de Baena (77-78), Barrera y Leirado (221) e Igartúa Landecho (6-13).

En lo que se refiere a la localización de la producción literaria de López de Castro, hay que decir que sus obras están dispersas, dentro y fuera de España (la Biblioteca Nacional de España, el Institut del Teatre de Barcelona, la Bibliothèque Nationale de France o la British Library, entre otros). Para la lectura de las mismas, también se puede acudir a la reproducción que hace de ellas Igartúa Landecho en su citado trabajo.

Al menos este es el número de las piezas localizadas a día de hoy. También conviene advertir que, en la actualidad, no es posible datar con exactitud estos entremeses. Algunos de ellos han llegado hasta nosotros a través de ediciones impresas -a las que aludiremos llegado el momento-, en las que no figura el año concreto y, en algunos casos, ni siquiera el nombre del impresor (como en los entremeses titulados Los áspides de Cleopatra, El gato o Un ventero...). 
a referir a continuación: El informe sin forma; Los áspides de Cleopatra; El castigo de un celoso ${ }^{7}$; El derecho de los tuertos; Los indianos de hilo negro; El galán duende y la cuenta de Nochebuena; Un ventero y un ladrón, ¿cuál es mayor?; El gato; Los sastres desastrados y Los médicos a la moda. Son estas diez piezas entremesiles, concretamente sus elementos metateatrales, el objetivo del presente artículo.

\section{ANÁLISIS DE LA METATEATRALIDAD EN LAS PIEZAS ENTREMESILES DE LÓPEZ DE CASTRO}

Desde la publicación, en 1963, de la célebre obra Metatheatre. A New View of Dramatic Form, del estadounidense Lionel Abel, varias han sido las consideraciones vertidas sobre el tema, hasta el punto de que, en el momento presente, aún no existe consenso entre la crítica $^{8}$ en lo que a la conceptualización del metateatro se refiere. Por un lado, se hallan aquellos autores que manejan una visión muy amplia del fenómeno metateatral, como es el caso de Richard Hornby, a tenor de las siguientes palabras:

Las ediciones de los entremeses El castigo de un celoso y Los indianos de hilo negro sí están datadas, pero son ediciones póstumas, pues ambas corresponden al año 1793 y López de Castro muere -recordemos- en 1762. Respecto a El derecho de los tuertos y El galán duende..., sí se habrían publicado en vida del autor, ya que ambas piezas aparecen incluidas en piscatores relativos a los años cincuenta del siglo XVIII; es en estos años (específicamente, en el período comprendido entre 1752 y 1762) cuando, a juicio de Igartúa Landecho (9 y 411), López de Castro habría escrito la mayoría de sus obras. De todas formas, lo que sí parece claro es que dichos textos se habrían comercializado en la capital de España, de donde era originario el autor, ya que en casi todas las ediciones conservadas se remite a librerías madrileñas, tales como la de Antonio del Castillo (Gradas de San Felipe el Real) o la de Quiroga (calle de la Concepción Jerónima).

Hay dudas sobre la autoría de este último entremés, El castigo de un celoso, pues algunos investigadores, como Urzáiz Tortajada (241) lo consideran obra de Francisco de Castro (dramaturgo de finales del siglo XVII y principios del XVIII), autoría que ha sido rechazada en los últimos años por Martínez Rodríguez (104 y 345). Por el momento, y hasta que no se descubran nuevos datos que nos hagan pensar lo contrario, atribuiremos este entremés a José Julián, en línea con estudiosos anteriores, como Álvarez de Baena (79), Barrera y Leirado (221) y Aguilar Piñal (328).

Para no extendernos demasiado, aquí solo mencionaremos los autores más representativos. 
Briefly, metadrama can be defined as drama about drama; it occurs whenever the subject of a play turns out to be, in some sense, drama itself. There are many ways in which this can occur. In one sense, as I argued in the last chapter, all drama is metadramatic, since its subject is always, willy-nilly, the drama/culture complex. A playwright is constantly drawing on his knowledge of drama as a whole (and, ultimately, culture as a whole) as his "vocabulary" or his "subject matter". At the same time, his audience is always relating what it sees and hears to the play as a whole, and beyond that, to other plays it has already seen and heard, so that a dramatic work is always experienced at least secondarily as metadramatic. Metadrama is thus not a narrow phenomenon, limited to a few great playwrights or to a few periods in theatre history, but is always occurring. Nevertheless, the manner in which a given play is metadramatic, and the degree to which the metadramatic is consciously employed, can vary widely. Great playwrights tend to be more consciously metadramatic than ordinary ones, and their plays to employ metadramatic devices more obviously, because the great playwright conceives his mission to be one of altering the norms and standards by which his audience views the world, and is thus more likely to attack those norms frontally. But again, this is only a tendency, and in fact every metadramatic device found in great plays can also be found in ordinary ones, even among the most crass and pedestrian. The possible varieties of conscious or overt metadrama are as follows: 1 . The play within the play. 2 . The ceremony within the play. 3 . Role playing within the role. 4. Literary and real-life reference. 5. Self reference (Hornby 31-32).

Como vemos, este autor distingue hasta cinco formas de metateatralidad, algunas de ellas muy cuestionables (como la alusión, dentro de una obra dramática, a aspectos de la vida real, pues esta última es entendida a su vez como un espectáculo teatral [theatrum mundi]).

En el polo opuesto a la línea representada por Hornby se sitúa Georges Forestier; para este estudioso francés, el metateatro se reduce al théâtre dans le théâtre, lo que

consiste à inclure un spectacle dans un autre spectacle; autrement dit, il s'agit avant tout d'une structure [...] Mais qu' entend-on exactement par théâtre dans le théâtre? Car il ne suffit pas de parler d'introduction d'un spectacle dans un autre. Qu' est-ce, en effet, qu'un spectacle? [...] Il y a théâtre dans le théâtre à partir du moment où un au moins des acteurs de la pièce-cadre se transforme en spectateur (Forestier 10-11). 
Entre ambas vías, la aperturista de Hornby y la más restrictiva de Forestier, se incardinan las propuestas de otros autores; uno de los más destacados y reconocidos es el profesor Alfredo Hermenegildo Fernández, que se ha dedicado ampliamente a esta cuestión en numerosos trabajos. En opinión de este hispanista burgalés, son dos fundamentalmente las manifestaciones del fenómeno metateatral: el teatro en el teatro $(\mathrm{TeT})$ y el teatro sobre el teatro (TsT). Con el primer concepto (TeT), Hermenegildo sigue muy de cerca las aportaciones de Forestier (théâtre dans le théâtre, oeuvre-cadre, oeuvre enchâssée, spectateurs intérieurs...) mientras que, bajo el segundo (TsT), subyacen algunas de las formas de metateatralidad de las que hablaba Hornby (como la self reference). La de Alfredo Hermenegildo es, por tanto, una propuesta de carácter integrador, pues logra aunar algunos de los planteamientos más relevantes existentes hasta hoy sobre el metateatro; razón por la cual la tomaremos como punto de partida para nuestro análisis de los entremeses de López de Castro. En consecuencia, las líneas que siguen girarán en torno a las dos nociones teóricas anunciadas arriba, el teatro en el teatro y el teatro sobre el teatro, en las que profundizaremos con vistas a aclarar el panorama aquí bosquejado.

\subsection{El teatro en el teatro (TeT)}

Comenzaremos por la forma más genuina del TeT, que consiste en la inclusión, dentro de una obra marco o englobante, "de una obra interior u obra enmarcada, engarzada, engastada" (Hermenegildo Fernández, "El personaje espectador" 127; "Mirar en cadena" 80); esto es lo que observamos en Los áspides de Cleopatra, de José Julián López de Castro. En este entremés (obra marco) se nos presenta a dos majos, Meregildo y Zaragalla, que están enamorados, respectivamente, de la marquesa doña Paca Cantimploras y de la criada de esta. Aconsejados por Holofernes, paje de la marquesa, ambos hombres acuden a la tertulia que aquella celebra todas las noches en su casa. Doña Paca y su criada reciben con bastante complacencia a Meregildo y Zaragalla, con los cuales pretenden divertirse un rato; es por ello que deciden organizar una representación dramática (obra enmarcada), en la que intervienen como actores la marquesa y Meregildo; estos últimos se convierten, así, en personajes

mirados por los otros dos personajes presentes en la escena, Zaragalla y la 
criada, que funcionan como espectadores o mirantes; a su vez, todo ello es contemplado por el público espectador, el archimirante 9 .

Tanto los personajes mirantes de esta pieza como los mirados son omniscientes, en la medida en que "asumen su condición teatral, fingida, mimética" (Hermenegildo Fernández, "Mirar en cadena" 82; "Usos de la metateatralidad" 215); en otras palabras, dichos personajes tienen absoluta consciencia de que lo que representan (doña Paca Cantimploras y Meregildo) o ven representar (Zaragalla y la criada) es irreal. Asimismo, mirantes y mirados ejercen, en este entremés, las funciones propias de conceptor y/o director escénico, una posibilidad de la que también hablaba Alfredo Hermenegildo ("Mirar en cadena" 82; "Usos de la metateatralidad" 215); esto sucede momentos antes de dar comienzo la representación de la obra enmarcada, como vemos en el siguiente fragmento:

\begin{tabular}{ll} 
MEREGILDO & $\begin{array}{l}\text { Yo hiciera en aquesta alcoba, } \\
\text { de los Áspides... }\end{array}$ \\
MARQUeSA & \multicolumn{1}{c}{$\begin{array}{c}\text { Prosigue. } \\
\text { [MEREGILDO] }\end{array}$} \\
& $\begin{array}{l}\text { De Cleopatra, señora, } \\
\text { un paso; pero no tengo } \\
\text { quien haga la dama en forma. }\end{array}$ \\
MARQUESA & $\begin{array}{l}\text { No te detengas por eso; } \\
\text { yo le haré que ni cotorra. }\end{array}$ \\
MEREGILDO & $\begin{array}{l}\text { Pues entremos a vestirnos } \\
\text { para que esto se disponga. }\end{array}$ \\
MARQUESA & $\begin{array}{l}\text { Sí, vamos a los desvanes, } \\
\text { que alli está mi guardajoyas. Vase. }\end{array}$
\end{tabular}

9 No nos detenemos en la explicación de estos conceptos (mirado, mirante y archimirante) pues Alfredo Hermenegildo ya los aborda minuciosamente en muchos de los trabajos que citaremos en estas páginas y que se recogen en la bibliografía del presente artículo, por lo que remitimos a ellos. No obstante, sirva a modo de ejemplo el siguiente fragmento extraído de uno de los estudios del citado profesor: "Es decir, el TeT supone la transformación de ciertos personajes de la comedia/marco en público, en espectador, en personaje mirante, y la asunción, por parte de otras figuras, de una nueva función dramática que les da la categoría de personaje mirado. A ciertas figuras de la comedia/marco se les confían nuevos roles, nuevas funciones que definirán y dramatizarán la 'puesta en escena' de la comedia engastada o interior [...] Evidentemente el público de la comedia/marco, será el archimirante, el espectador supremo" ("Sombras escénicas" 49). 
Zaragalla $\quad Y$ entre tanto...

DAMA

Zaragalla

¿Qué?

Bailar

dos seguidillas nos toca.

[...] (10-11. La cursiva es mía) ${ }^{10}$.

Como toda muestra de TeT, el entremés de López de Castro que ahora comentamos viene a ser "una especie de teatro al cuadrado o teatro reduplicado que implica como mínimo la existencia de dos niveles de representación" (Zugasti Zugasti 58): un nivel superior en el que se sitúa la obra marco (o "ficción de primer grado" [Canonica 132]) y un nivel inferior o más profundo constituido por la obra enmarcada (o "ficción de segundo grado" [Canonica 132]). De la convivencia de ambos niveles se produce un doble efecto, aparentemente contradictorio: gracias a la obra enmarcada, la obra marco adquiere mayor realismo ya que "si el público contempla, porque ha visto cómo se pone en marcha, el carácter ficticio de la obra enmarcada, reaccionará ante la obra englobante como si se tratara de la verdadera vida" (Hermenegildo Fernández, "Usos de la metateatralidad" 214); pero, al mismo tiempo, "la obra enmarcada, por su carácter abiertamente fictivo, puede modificar también la percepción de la obra englobante y poner de relieve su condición no-real, su dimensión inventada, su consistencia estrictamente teatral, fingida" (Hermenegildo Fernández, "Mirar en cadena" 81; "Usos de la metateatralidad" 214) ${ }^{11}$.

Por el momento, baste con lo dicho hasta aquí sobre Los áspides de Cleopatra de López de Castro - texto del que luego se darán algunas pinceladas complementarias-y pasemos a centrarnos en los restantes entremeses del dramaturgo madrileño.

10 Para las citas de este entremés, seguimos un ejemplar impreso de la Biblioteca Nacional de España, signatura: T/25794. Tanto en el caso que nos ocupa, como en todos los demás entremeses de López de Castro que estudiamos, después de la cita textual en cuestión se colocará entre paréntesis el número de la página o del folio -siempre que lo haya- en que esta se encuentra. Asimismo, modernizamos la ortografía y desarrollamos las abreviaturas, aunque conservamos los rasgos morfosintácticos de los textos para mantener, hasta cierto punto, la peculiaridad de los mismos.

11 Para más detalles sobre este asunto, véase el estudio de Hermenegildo Fernández et al. (10-11). 
Dichos entremeses se catalogarían como "de acción” (según la clasificación propuesta por Huerta Calvo [87]), puesto que se basan en la ejecución de una burla, la cual puede responder tanto a motivaciones económicas como de índole sentimental. Por razones organizativas, dividiremos nuestro análisis en estos dos grupos de entremeses: empezaremos por los de temática amorosa, por constituir la parte más relevante, desde el punto de vista cuantitativo, de la producción dramática de López de Castro; posteriormente, hablaremos de los entremeses de motivaciones económicas.

Lo primero que habría que aclarar es que, en estas piezas, el TeT no se manifiesta en la forma pura (obra enmarcada dentro de una obra marco) que acabamos de analizar en Los áspides de Cleopatra -de ahí que este entremés haya sido tratado aparte-, sino en sus formas derivadas. Para iluminar este punto, conviene traer a la memoria las consideraciones realizadas al respecto por Alfredo Hermenegildo:

La presencia del TeT se manifiesta y ejerce su influencia en la teatralización más allá de lo que supone la presencia de una obra enmarcada e identificada como pieza teatral. Siempre que un personaje se revista de una función distinta de la que le es propia en la obra/marco, siempre que alguna de las figuras dramáticas asuma una función de público, de mirante, frente a las otras figuras, los mirados, y siempre que haya dentro de la acción de una pieza la puesta en escena de otra acción en cierto modo autónoma, estamos ante formas de teatralidad que pueden y deben estudiarse como variantes del TeT o derivadas, de modo inmediato, de él ("Usos de la metateatralidad" 212) 12 .

En los entremeses amorosos de López de Castro, el objetivo fundamental de la acción dramática consiste casi siempre en liberar a la dama de las manos de su despótico tutor (padre, hermano o tío de la joven). El medio habitual para alcanzar ese fin por parte de los galanes es llevar a cabo un fingimiento que les permita infiltrarse fácilmente en casa del tutor de la dama y, una vez en ella, entretener a este el tiempo necesario para la huida de la muchacha. Dicho fingimiento implica que los galanes (y, en ocasiones, algún amigo o colaborador de estos) adopten "una función distinta de la que le[s] es propia en la obra/marco" -como decía Hermenegildo-, para lo que recurren, en

12 Estas consideraciones también pueden consultarse en Hermenegildo Fernández ("Mirar en cadena" 79; "Sombras escénicas" 25). 
ocasiones, a un disfraz. Veamos algunos ejemplos concretos: Trabuco ( $E l$ galán duende o la cuenta de Nochebuena) se presenta en casa de su amada Marta y se hace pasar por un fantasma ("Sale Trabuco embozado, vestido de fantasma y sin descubrir la luz, que trae en una linterna" [75] $\left.{ }^{13}\right)$, con lo que suscita el terror de Naranjo, hermano de Marta; Bartolo, Martincho y el gracioso (Los indianos de hilo negro) toman la apariencia de indianos para engañar a don Judas Rompesquinas y liberar a Catanla, Pretona y Pacorra, hijas de don Judas; Zapatilla (El informe sin forma), vestido de estudiante y en compañía de su amigo Trullo, logra entrar en casa de su querida Escotofia y allí burla al avaricioso doctor Moreno, padre de la joven, que ha tomado a Zapatilla por un importante forastero; Cagurria Mamatesa ( $\mathrm{El}$ derecho de los tuertos) también toma por forasteros a Badulaque y Zangandungo, cuando estos últimos se presentan en su casa "con parches en los ojos" (s. $\left.\mathrm{p} .{ }^{14}\right)$ y acompañados de Mamacallos, que viene disfrazado "de paje" (s. p.); Bartolo, Tarugo y Gerundio (Los médicos a la moda), amantes de Pretona, Melchora y Fabiana, respectivamente, fingen ser médicos que vienen a asistir al vizconde de Malpaga, hermano de aquellas tres, quien, por fiarse de los falsos doctores, acaba siendo manteado por estos; Tarugo y su amigo Malayas (Los sastres desastrados) consiguen penetrar en la vivienda de Cornelio Oruga disfrazados de sastres y, tras haberse burlado de este haciéndole probar un hábito pequeño con el que lo tiran al suelo, huyen con Catuja, la sobrina del vejete y amada de Tarugo. Finalmente, conviene mencionar El castigo de un celoso, entremés que, aunque de temática amorosa, dista de los mencionados arriba por el hecho de que la burla no está ejecutada por un galán hacia el tutor de la dama, sino por una mujer hacia su esposo; por lo demás, en esta pieza también se produce un fingimiento equiparable a los analizados anteriormente: la joven Lucrecia, encerrada en casa por su viejo y celoso marido, consigue ser liberada por una vecina, de nombre Preciosa; por medio de esta última, Lucrecia se entera de que Domingo -así se llama el marido- se ha marchado al madrileño Paseo del Prado a flirtear con otras mozas, aprovechando el encierro de su mujer. En venganza por el comportamiento del vejete, Lucrecia y Preciosa, que camuflan su identidad

13 Para las citas de este entremés, seguimos un ejemplar impreso de El piscator de las damas o Los cármenes de Granada, en el que se publicó El galán duende o la cuenta de Nochebuena; Biblioteca Nacional de España, signatura: RI/342<18>(2).

14 Este entremés también salió a la luz integrado en un piscator, concretamente en $E l$ piscator de las damas o La quinta de Manzanares. Citamos según un ejemplar impreso de este piscator conservado en la Biblioteca Nacional de España, signatura: RI/342<15>(3). 
con vestidos de majas, acuden al Prado al encuentro de Domingo, quien, tras ver a ambas mujeres, no duda en insinuárseles. Con la intervención de un tercer personaje, un bravucón compinchado en la burla, Lucrecia y Preciosa acaban escarmentando al vejete, al que no le queda más remedio que pedir perdón a su esposa.

Como probablemente se haya podido deducir a estas alturas, el fingimiento que llevan a cabo los personajes indicados en las líneas anteriores viene a constituir "la puesta en escena de otra acción en cierto modo autónoma" a la acción de la pieza principal, retomando las palabras de Alfredo Hermenegildo arriba reproducidas; en dicha 'puesta en escena', unos personajes se convierten momentáneamente en actores (mirados) que, sirviéndose a veces de un disfraz (trasunto del vestuario teatral), representan un determinado papel (el de médico, sastre, indiano, forastero, etc.) ante otros personajes que actúan de espectadores (mirantes); entre estos últimos, los mirantes, ocupa un lugar destacado el tutor (padre / hermano / tío / marido -caso este último de El castigo de un celoso-) de la dama, en cuanto principal destinatario de la burla. Frente a los mirados (los ejecutores de la burla), de condición omnisciente, los mirantes (los tutores de las damas) son nescientes ${ }^{15}$, es decir, desconocen el carácter ficticio, irreal de lo que están presenciando, algo que resulta "fundamental para que funcione la representación como engaño", pues "si el nesciente, el ignorante, pasa a la categoría de omnisciente, la burla se rompe y la situación se deshace" (Hermenegildo Fernández, "Usos de la metateatralidad" 215).

Una vez analizada la presencia del TeT en los entremeses amorosos de López de Castro, abordaremos esta misma cuestión, de manera breve, en aquellos entremeses del escritor madrileño en los que la burla no está motivada por factores sentimentales sino económicos. Contamos únicamente con dos piezas de este tipo: El gato y Un ventero y un ladrón, ¿cuál es mayor? En ambas obras, al igual que ocurría en los entremeses de burla amorosa, el TeT no aparece en su expresión más pura, sino en sus formas derivadas, como comprobaremos seguidamente.

15 Cuando aquí hablamos de mirantes nescientes, nos estamos refiriendo exclusivamente a los tutores de las damas -como ya se ha dicho-y no al resto de posibles personajes mirantes que pudieran haber visto el fingimiento (como, por ejemplo, las propias damas, que con frecuencia también se hallan presentes en la burla). A diferencia de sus tutores, las damas sí serían mirantes omniscientes, pues conocen desde el principio la naturaleza ficticia de la acción representada por los galanes. 
En El gato, un ladrón, de nombre Zascandil, pretende robar la bolsa del dinero a Pelagallos, hombre sordo que regenta una barbería. Zascandil, fingiendo ser una persona de bien, honrada y cortés (como él mismo confiesa antes de dar comienzo a su plan: "Voy a robarle atento y humillado, / que soy ladrón, pero soy hombre honrado $\left.[2]^{16}\right)$, se presenta en la barbería con la excusa de afeitarse. Durante el rasurado, Zascandil relata a Pelagallos una historieta sobre un gato, con la que lo distrae mientras le roba la bolsa del dinero, que el barbero guarda celosamente en su bolsillo. La misma habilidad para el latrocinio y el fingimiento parecen poseer Lagarto, Uñate y Candonga, en Un ventero... Estos maleantes van a la venta de Chupacandiles con la intención de comer de balde, aprovechando que el criado del ventero, llamado Tragaldabas, se encontraba solo. Para ganarse la confianza de este último, los vividores le hacen creer que son gente acaudalada; de hecho, Lagarto declara ser un caballero de la corte ("No, que yo soy hombre tan aplaudido / que, en todas partes, hago mucho ruido, / porque soy de altos humos caballero" $\left.[7]^{17}\right)$. En el colmo del descaro, cuando llega la hora de pagar, Lagarto, Uñate y Candonga aparentan reñir entre ellos por ver quién salda la cuenta, lo que deja sorprendido a Tragaldabas, que acaba concluyendo que "quimera por pagar e[s] cosa nueva" (11). Finalmente, los rufianes consiguen abandonar la venta tras dejar al criado con los ojos tapados y con el convencimiento de que debía ser él mismo quien, por medio del sistema de la gallina ciega, eligiera al pagador.

En resumidas cuentas, tanto en El gato como en Un ventero..., asistimos al fingimiento / puesta en escena, dentro de la acción principal del entremés, de una acción secundaria desarrollada por unos personajes mirados (Zascandil; Lagarto, Uñate y Candonga) en presencia de unos mirantes (Pelagallos; el criado del ventero).

\subsection{El teatro sobre el Teatro (TsT)}

Como suele ser frecuente, el TeT no aparece solo en los entremeses de López de Castro, antes bien, está acompañado de la otra cara del fenómeno

16 Para las citas de este entremés, seguimos un ejemplar impreso de la Biblioteca Nacional de España, signatura: R/18276(25).

17 Para las citas de este entremés, seguimos un ejemplar impreso de la Biblioteca Nacional de Francia, signatura: 8-YTH-65648. 
metateatral, el TsT; este último consiste en "la reflexión misma sobre el hecho teatral y su historia, la teatralidad, los mecanismos que rigen la escena, etc..." (Hermenegildo Fernández, "Mirar en cadena" 79; "Sombras escénicas" 25). Aunque el TsT puede manifestarse de muy diversas maneras, en el teatro breve de López de Castro lo hace fundamentalmente en forma de referencias y autorreferencias ${ }^{18}$.

\subsubsection{REFERENCIAS}

Son múltiples los elementos del universo dramático que pueden aparecer reflejados en las piezas breves; uno de ellos es el lenguaje teatral, aspecto sobre el que encontramos numerosas referencias en los entremeses de López de Castro. El primer ejemplo que traemos a colación proviene de El informe sin forma, donde Zapatilla nos habla de su amada Escotofia en los siguientes términos:

ZaPATILLA $\quad$ ¡Ay, amigo, que soy un desdichado!
Ya sabes cuántos años ha que peno
por la chiquilla del doctor Moreno,
aquella cuyos ojos bailarines
a tantas almas hacen volatines;
cuyas rojas mejillas
al mismo dios de amor hacen cosquillas,
porque de su garboso cerviguillo,
aun no sabe librarse Cupidillo.
Correspondido de esta muchos días,
consuelo hallaron las delicias mías,
y cuando mi esperanza loca y vana
suyo esperaba de hoy a mañana,
muere en flor mi cuidado.
¡Ay, amigo, que soy un desdichado! $(2)^{19}$

18 A este respecto, véase Martínez López (254-261).

19 Para las citas de este entremés, seguimos un ejemplar impreso de la Biblioteca Nacional de España, signatura: T/55359/87 
A nuestro modo de ver, en estos versos López de Castro viene a simular, desde una perspectiva burlesca, el conocido código petrarquista ${ }^{20}$ al que recurrían manidamente muchos comediógrafos de la época para la confección de sus obras. Lo mismo ocurre, de manera más clara si cabe, en El derecho de los tuertos; para no extendernos en la cita, recogemos únicamente aquellos fragmentos que más nos interesan:

BADULAQUE
La hermosura de acitrón,
el sol de azúcar rosado,
la boca de mermelada,
los pechos de manjar blanco,
la cintura de alfeñique
y el pie de huevos hilados.
$[\ldots]$
Apenas con su belleza,
dieron de hocicos mis labios,
$[\ldots]$
hallé todo el entresijo
con un dolor entripado,
a manera del que tienen
el mes de enero los gatos.
$[\ldots]$
por lo que alegre de ver
la breva ya madurando,
y triste de contemplar
entre paredes el árbol,
melancólico y contento,
gozoso y desesperado,
en el tocino de amor,
estoy entre gordo y magro.
$[\ldots]$
Pues, amigos, yo por ella
el vientre tengo tan malo,
que al punto que me da un aire
despido truenos y rayos.
$[\ldots] \quad$ (s. p.)

20 En ese código era muy frecuente, a la hora de describir la fisonomía de la amada, mencionar los ojos o las mejillas, como se hace en los versos reproducidos; véase Manero Sorolla (14-30). 
Como ya avanzábamos en otro lugar ${ }^{21}$, el modo chocarrero en que Badulaque describe a Tarumba pone en solfa las fórmulas de la descriptio puellae petrarquista ${ }^{22}$; igualmente, los adjetivos que elige este personaje para transmitir su congoja amorosa ("melancólico y contento, / gozoso y desesperado") estarían parodiando los oxímoros de los que tantas veces se abusaba en las comedias.

La misma intención paródica parece mover a López de Castro en la representación teatral (obra enmarcada) que incluye dentro de su entremés Los áspides de Cleopatra (obra marco) -antes citado-; en dicha representación, Meregildo, en el papel del triunviro Marco Antonio, y la marquesa, en el de la reina egipcia Cleopatra, se enzarzan en una pelea, durante la cual se profieren insultos bastante toscos; sirvan de muestra los siguientes:

$21 \quad$ Véase Federico Briante Benítez (2019).

22 En relación a lo que explicamos, conviene apuntar el enorme peso que tuvo Petrarca en la literatura española, pudiéndose rastrear las huellas del autor del Canzoniere no solamente en el teatro, sino también en la poesía o la narrativa; en consecuencia, las citadas alusiones petrarquistas que aparecen en los dos entremeses de López de Castro que ahora comentamos podrían considerarse referencias de carácter metaliterario, más que propiamente metateatrales. Ahora bien, si hemos optado por esto último es porque López de Castro parece partir de fuentes dramáticas para crear la gran mayoría de sus entremeses (lo que nos lleva a pensar que son estas mismas fuentes de donde procede principalmente la cómica recreación del código petrarquista que se refleja en dichos entremeses), a saber: para Un ventero y un ladrón, el escritor madrileño se habría inspirado en el entremés Este lo paga, de Jerónimo de Cáncer; para Los sastres desastrados, López de Castro partiría de otro entremés, El zapatero y don Terencio Catalana, atribuido a Antonio Enríquez Gómez; por su parte, el entremés El gato habría bebido de El borracho, de Quiñones de Benavente (Cotarelo y Mori lxxviii; Fernández Gómez 327); en el caso de El informe sin forma, la fuente no está tan clara, pero todo apunta nuevamente hacia referentes teatrales, tales como La burla de Pantoja y el doctor, de Agustín Moreto, y la pieza anónima El pleito del mochuelo; igual ocurre con El castigo de un celoso, obra que podría relacionarse con El viejo celoso, de Miguel de Cervantes, o con Los refranes del viejo celoso (este último es de atribución quevediana, si bien Madroñal Durán [2013] lo considera de Luis Quiñones de Benavente); por último, para El galán duende y la cuenta de Nochebuena, también pueden barajarse distintas fuentes, como La dama duende, de Calderón de la Barca, y más posiblemente, el entremés El duende, de Diego de Torres Villarroel; en el caso de otros entremeses como El derecho de los tuertos, no disponemos de información precisa a este respecto. No obstante, creemos que los datos facilitados anteriormente evidencian una clara predilección de López de Castro por las fuentes teatrales como manantial del que nutrir su producción entremesística. 
MEREGILDO

MARQUeSA

MEREGILDO
¡Oh, gran bellaca!

¿No me das un abrazo?

Toma.

Daca;

¿pero yo sujetarme a una pindonga? (13)

A través del comportamiento pedestre que exhiben ambos personajes, López de Castro parece burlarse del carácter sublime e idealizado que solía caracterizar las relaciones sentimentales entre los galanes y las damas en muchas obras del teatro español; una de estas obras podía ser la que escribió el toledano Francisco de Rojas Zorrilla entre 1640 y 1645 (González Cañal 269), donde se pone en escena la sublime pasión amorosa entre Marco Antonio y Cleopatra y que se titula, para más señas, Los áspides de Cleopatra ${ }^{23}$, curiosamente el mismo título en el que se basan Meregildo y la marquesa para la obra (enmarcada) que escenifican, recordemos:

$\begin{array}{cc}\text { Meregildo } & \begin{array}{l}\text { Yo hiciera en aquesta alcoba, } \\ \text { de los Áspides... } \\ \text { MARQuesa }\end{array} \\ \text { Meregildo } & \begin{array}{c}\text { Pe Cleopatra }, \text { señora, } \\ \text { un paso [...] }(10) .\end{array}\end{array}$

En pocas palabras, con la pequeña representación que López de Castro inserta en su entremés, el dramaturgo madrileño nos remite a la citada obra de Rojas Zorrilla -aunque contemplada esta desde una perspectiva jocosa-, de modo que estaríamos aquí ante un caso de TsT dentro de un TeT.

Otro entremés de López de Castro donde se evoca el título de una célebre comedia española de época áurea - dando cabida de este modo, nuevamente, al TsT- es El galán duende y la cuenta de Nochebuena; en la primera parte de esta pieza, Trabuco conversa con Marta, la cual da cuenta a su amante de las penurias a las que la somete su hermano Naranjo. Durante el transcurso de dicha conversación, una vez resuelto Trabuco a disfrazarse de fantasma para liberar a Marta y viendo la buena disposición de esta para la fuga, el

23 Es muy probable que López de Castro conociera bien esta obra de Rojas Zorrilla, pues Los áspides de Cleopatra fue uno de los textos del autor toledano que contó con un mayor número de representaciones e impresiones en sueltas durante el siglo XVIII. Véanse al respecto los trabajos de Arenas Cruz (2000) y González Cañal (2008). 
joven se refiere a su amada como "Marta piadosa", en clara referencia a la comedia de Tirso de Molina y a su intrépida protagonista ${ }^{24}$ :

\begin{tabular}{|c|c|}
\hline $\begin{array}{l}\text { TRABUCO } \\
\text { MARTA }\end{array}$ & $\begin{array}{l}\text { Pues haz cuenta que escapas de sus redes. } \\
\text { ¡Jesús! ¿Cómo ha de ser? }\end{array}$ \\
\hline TrabuCO & Ya lo veredes. \\
\hline & ¿Te querrás tú salir? \\
\hline MARTA & Y muy gustosa. \\
\hline Trabuco & Eres Marta, por fin, Marta piadosa. \\
\hline MARTA & Pues, ¡a la empresa! \\
\hline Trabuco & A la invasión. \\
\hline Los DOs & Al cuento. \\
\hline MARTA & Al miserable. \\
\hline Trabuco & Al ruin. \\
\hline Los DOS & $\mathrm{Al}$ avariento (69). \\
\hline
\end{tabular}

Poco a poco vamos confirmando la finalidad del TsT que adelantábamos más arriba en palabras de Alfredo Hermenegildo ("Sombras escénicas" 25), esto es, reflexionar, incidir en aspectos tocantes al "hecho teatral y su historia"; algunos de estos aspectos ya han aparecido: el lenguaje teatral, los autores dramáticos (Francisco de Rojas Zorrilla, Tirso de Molina...), etc. Detengámonos ahora en otro aspecto de la historia teatral no menos importante: el público, concretamente el femenino. Sabido es que, durante mucho tiempo, el gusto del pueblo español por el teatro fue generalizado, prácticamente sin distinción de sexos. Las mujeres sentían hacia las representaciones teatrales la misma, o incluso más, afición que los hombres. Así lo acredita, para el caso del Setecientos, el hispanista René Andioc en su libro Teatro y sociedad en el Madrid del s. XVIII; en esta importante obra, el estudioso galo (50) nos habla, por ejemplo, del enorme interés que despertaban las comedias de magia entre el público femenino. López de Castro no viviría ajeno a este hecho, de ahí que las protagonistas de sus piezas breves expresen, con bastante frecuencia, a sus tutores el deseo de asistir al teatro o a los toros, que eran las dos principales

24 Otra posible comedia áurea a la que podría estar refiriéndose este entremés es $L a$ dama duende, de Calderón de la Barca. No solo el propio título del entremés (El galán duende...) podría estar aludiendo a la comedia calderoniana, sino también su argumento, puesto que, del mismo modo que en La dama duende, en la pieza de López de Castro aparece la figura del hermano opresor que coarta las ansias amorosas de la dama protagonista. 
diversiones populares por aquel entonces; un ejemplo de lo que comentamos lo tenemos en Catuja (Los sastres desastrados):

$\begin{array}{ll}\text { Catuja } & \text { ¿Es posible que viva en tal tragedia, } \\ & \text { que no he de ver ni toros ni comedia? } \\ \text { Ve, bribona, tu gusto mal pretende; } & \text { yo me entiendo, sobrina, y Dios me entiende. } \\ & \text { Las comedias son buenas sin percances, } \\ \text { pero suelen traer muy malos lances. } & \\ & \text { Una función de toros no es molesta, } \\ & \text { pero si una mujer va a alguna fiesta, } \\ & \text { en habiendo otras con sus amiguillos, } \\ \text { hacen por ver los toros mil novillos. } & {[\ldots](6)^{25} .}\end{array}$

Lo mismo se aprecia en Tarumba (El derecho de los tuertos):

$\begin{array}{ll}\text { TARUMBa } & {[\ldots]} \\ & \text { pues habemos de entrar en la comedia. } \\ \text { VeJeTE } & \text { ¿Vosotras en comedias? Anda fuera, } \\ & \text { antes os haré entrar en la galera. } \\ & \text { Oiga, oiga las marisabidillas, } \\ & \text { qué amigas son de bailes las zorrillas. } \\ \text { Quiteria } & \text { Pues si mi tía doña Angaripola } \\ & \text { hace primera dama por la cola, } \\ & \text { ¿no será que faltemos grosería? } \\ \text { VeJETE } & \text { Pues, amiga, cuéntaselo a tu tía } \\ & \text { porque yo, aunque mis años no son tiernos, } \\ & \text { teniendo tantas canas como cuernos, } \\ & \text { no tengo de sufriros ni pasaros. } \\ & \text { ¿Que con motivo de ir a ensayonaros } \\ & \text { en el papel o en el del galanteo, } \\ \text { andéis todas las noches de bureo?; } & \text { ¿que mientras se comienza el festín vario, }\end{array}$

25 Para las citas de este entremés, seguimos el ejemplar impreso de la British Library, signatura: 11726.aa.1.(5.) 
retozando os estéis en el vestiario? ${ }^{26}$; ¿que admitáis de un galán que por vos muere la cinta, el traje y lo que el diablo quiere? ¿que en la comedia un majo muy severo bese a las dos, como así me las quiero, sin que pueda impedirse tal fracaso, $[\ldots]$ No, hijas mías, mil fiestas os renuncio, pero lo que es comedias abernuncio (s. p.).

Como vemos, en el fragmento que acabamos de reproducir no solo se alude al tipo de público que solía frecuentar los coliseos, sino también a otros elementos de la historia teatral, como la organización de las compañías teatrales, con sus galanes, damas, barbas, graciosos, etc. ("hace primera dama por la cola").

Este último asunto (organización de las compañías teatrales) aparecía asimismo en Los áspides de Cleopatra, por boca de Meregildo; recordemos los versos en cuestión: "De Cleopatra, señora, / un paso; pero no tengo / quien haga la dama en forma" (10). Poco después, en ese mismo fragmento, también se menciona el vestuario de los actores ("Pues entremos a vestirnos / para que esto se disponga [...]" [10]). Todas estas alusiones se producen como preparación previa a la representación dramática desarrollada por Meregildo y la marquesa dentro del entremés; por consiguiente, dichas alusiones supondrían, empleando unas palabras de Zugasti Zugasti (59), "toda una batería de datos de TsT que sirven para preparar al público archimirante ante la llegada de un pasaje de TeT".

La última referencia metateatral que comentaremos en relación a los entremeses de López de Castro se encuentra en El informe sin forma; concretamente, en la primera parte de la pieza, cuando Zapatilla habla de Escotofia como "aquella cuyos ojos bailarines / a tantas almas hacen volatines"(2); con el empleo de esta última palabra (volatines), el dramaturgo nos conduce, consciente o inconscientemente, a un tipo de espectáculo homónimo, harto frecuente en su época, que consistía grosso modo en juegos acrobáticos. No se trata, por tanto, de una actividad puramente teatral, pero forma parte del mundo de las 'variedades', un ámbito que, como señalaba hace años Miguel

26 Deformación de la palabra vestuario, debido al habla temblona característica de los vejetes entremesiles (Huerta Calvo 108). 
D'Ors (645), resulta "muy difícilmente separable del mundo teatral" en el

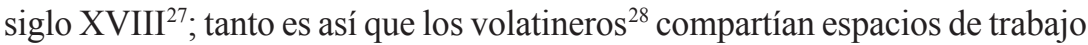
con los actores de las compañías teatrales, quienes cedían a los primeros los corrales de comedias (posteriormente, coliseos) durante el tiempo de Cuaresma, período en que se suspendían las representaciones dramáticas. Por todo ello, consideramos que la citada mención a los volatines que se hace en El informe sin forma podría entenderse como metateatral.

\subsubsection{Autorreferencias}

Hasta aquí hemos examinado ejemplos de TsT basados en la referencia a aspectos generales (autores, público, compañías, vestuario, etc.) del hecho teatral y su historia. Veremos ahora otros casos en los que López de Castro, dejando al descubierto más que nunca su consciencia de entremesista, abre la puerta en sus piececitas a alusiones específicamente relacionadas con el mundo del entremés; de ahí que, siguiendo a María José Martínez López (259-261), hayamos reunido este conjunto de alusiones bajo el marbete de "autorreferencias".

Uno de los rasgos más conocidos de los entremeses es la onomástica grotesca de sus personajes, que puede evocar aspectos culinarios, escatológicos, defectos físicos o de carácter, etc. (Fernández Oblanca 60), siempre dentro del afán cómico-burlesco que se persigue en este tipo de obras. En ocasiones, en los entremeses de López de Castro algunos personajes aluden a dicho motivo, "conscientes de que son personajes grotescos en un mundo de ficción, es decir, que están representando un rol determinado" (Hernández Martín 39); así, en El derecho de los tuertos, Badulaque alude al nombre de su amada Tarumba del siguiente modo: "Pues vamos, que si consigo / echar a esta maula el gancho, / con mi Tarumba esta noche, / la tarumba y tamba canto" (s. p.). Lo mismo hace Martincho con Pretona en Los indianos de hilo negro: "Más apretadas son mis aflicciones, / pues a Pretona van mis apretones" (4)

27 De hecho, Bernaldo de Quirós Mateo (70-78), por ejemplo, considera a los volatines (junto a diversiones similares como volteadores, títeres y danzas) dentro del grupo de las actividades parateatrales.

28 Para más información sobre títeres y volatines, véase el trabajo de Cornejo Vega (2016).

29 Para las citas de este entremés, seguimos un ejemplar impreso de la Biblioteca Nacional de España, signatura: R/18262(12). Asimismo, en la antología que elabora Ripodas Ardanaz (9-21) sobre la figura del indiano en el teatro breve también se incluye esta pieza. 
o Mendrugo, más adelante, en esa misma obra: "Pretona de mis tripas, por quien fina / me aflojo tantas veces la pretina, / abracémonos, hija, antes del parto" (15). Por último, en El galán duende y la cuenta de Nochebuena, el nombre de Trabuco también se convierte en objeto de comentario por parte de Marta: "¡Oh Trabuco, que el alma me desnucas, / cuando de arriba abajo me trabucas! / Trabuquito de amor, que, taimadazo, / has dado a mi desdén un trabucazo" (67).

Al igual que la onomástica grotesca, la vinculación con el Carnaval constituye otro de los rasgos idiosincrásicos más relevantes del teatro breve, de manera que la simple mención a las Carnestolendas ${ }^{30}$, contenida dentro de un entremés, adopta ineludiblemente visos metateatrales; es lo que apreciamos en El castigo de un celoso, cuya acción se sitúa en plena celebración del Carnaval, de lo que nos informa Lucrecia al poco de comenzar la pieza ("Hoy, que es Domingo de Carnestolendas" [2] ${ }^{31}$. Igual sucede en Los médicos a la moda; en este caso es Petronila quien nos da noticia de ello: “¿Día de Carnestolendas / y no haber fandango en casa? (fol. 7 r.) ) $^{32}$.

Cerramos este grupo de autorreferencias hablando de un aspecto no menos conocido de las piezas entremesiles, su peculiar forma de concluir; esta puede basarse en un baile, como nos recuerdan los personajes intervinientes en $E l$ castigo de un celoso, en los últimos versos de la obra:

\begin{tabular}{|c|c|}
\hline MAJO & El baile falta ahora. \\
\hline Todos & ¡Vaya el baile! Bailan \\
\hline VeJete & $\begin{array}{l}\text { Cornudo y apaleado } \\
\text { bailo al instante. }\end{array}$ \\
\hline Preciosa y Lucrecia & $\begin{array}{l}\text { Muchos hay en la corte, } \\
\text { que así lo hacen. }\end{array}$ \\
\hline TODOS & $\begin{array}{l}\text { Siga la danza, } \\
\text { que entremeses y bailes } \\
\text { bailando acaban (15-16). }\end{array}$ \\
\hline
\end{tabular}

30 Sobre las estrechas relaciones entre el teatro y el Carnaval, véase el trabajo de García Valdés (1997).

31 Para las citas de este entremés, seguimos un ejemplar impreso de la Biblioteca Nacional de España, signatura: R/18268(6).

32 Para las citas de este entremés, seguimos un ejemplar manuscrito de la Biblioteca Nacional de España, signatura: MSS/14529/13. 
Los entremeses también se clausuraban mediante la interpretación de una tonadilla, una costumbre que, como demuestra Cotarelo y Mori (cclxxxviiccxc) con multitud de ejemplos, no era inusual en los años en que vivió López de Castro. A esta costumbre estarían aludiendo los versos finales de Los áspides de Cleopatra:

\begin{tabular}{ll} 
Todos & Víctor ¿y ahora qué nos falta? \\
ZARAGALla & Una tonadilla airosa. \\
Meregildo & Pues a principiarla. \\
Todos & \multicolumn{1}{c}{ Vaya. } \\
ZARAGALLA & Corra, pues, la bulla. \\
Todos & Corra (14).
\end{tabular}

Otra fórmula de cierre propiamente entremesil consiste en el final a palos, posibilidad por la que parece optar El informe sin forma, como sugiere Zapatilla en el último verso de la obra:

ZAPATILLA

VEJETE

ZAPATILLA
De este modo. Danse las manos. Ya que por bien no viene en nuestros gustos vendrá después de haber tragado sustos. Ni por bien, ni por mal convengo en ello. Ya no es fácil volver a deshacello, y si por bien, ni mal ha de ajustarse, este es el mejor modo de acabarse. Remátase a palos tras el viejo (16).

\section{CONCLUSIONES}

Que el teatro breve resulta un territorio propicio para abordar "el tema de la autoconsciencia dramática" (Sáez Raposo 52) queda fuera de toda duda. Basta con acercarse a la obra de alguno de los numerosos entremesistas que han poblado las letras hispanas para comprobarlo, en mayor o menor grado. Aquí lo hemos querido hacer con uno de ellos, el madrileño José Julián López de Castro, poeta y dramaturgo del siglo XVIII completamente relegado al olvido en nuestros días, pese a tener una interesante producción literaria que, entre otros aspectos, testimonia la supervivencia de la tradición dramática áurea en la España dieciochesca. 
Las piezas entremesiles que de López de Castro se han conservado son bastante escasas, pero en ellas se despliega un amplio y variado programa de metateatralidad. Como hemos comprobado a lo largo de estas líneas, en sus entremeses es posible rastrear el teatro en el teatro (TeT) -desde la manifestación más genuina de este (obra enmarcada dentro de una obra marco) hasta sus formas derivadas-y el teatro sobre el teatro (TsT), por medio del cual se pone en circulación una gran cantidad de referencias y alusiones metateatrales de lo más diversas. Pensamos que este proceder de López de Castro no es resultado de la arbitrariedad ni de la indolencia frente al peso de la tradición literaria; muy por el contrario, responde a la personalidad del escritor ante el que nos encontramos, un escritor audaz, de genio vivo y conciencia crítica y con un gran sentido del humor (como se pone de manifiesto en algunas de sus obras poéticas -véase, por ejemplo, la Relación satírica y curiosa-).

Esto tampoco quiere decir que el gusto de López de Castro por la metateatralidad sea aislado en el siglo XVIII, sino que -intuimos- participa de una corriente mucho más amplia, en la que toman parte otros autores de la época; entre ellos, hay algunos nombres muy destacados como el gaditano Juan Ignacio González del Castillo (1763-1800) y el madrileño Ramón de la Cruz (1731-1794). Del primero conservamos, por ejemplo, el sainete Los cómicos de la legua; respecto a la faceta metateatral del segundo, a cuyo análisis se acercó hace años Ermanno Caldera (1977), esta se refleja en piezas como El repente de los cómicos, El pueblo quejoso, La compañía obsequiosa o La despedida de los cómicos.

Ahora bien, para confirmar esta intuición, juzgamos insuficiente el limitado espacio que nos brindan las páginas de un artículo científico; abordar rigurosamente esta cuestión requeriría de un estudio mucho más amplio que delimitara con exactitud el alcance que tuvo el fenómeno metateatral en el teatro breve español del Setecientos y los principales agentes que estuvieron implicados en el mismo.

Creemos que un estudio de conjunto con las características señaladas es de imperiosa necesidad para completar uno de los tantos vacíos de los que aún adolecen los estudios literarios sobre el siglo XVIII; de ahí la importancia del trabajo que ahora presentamos, con el que se pretende arrojar algo de luz sobre la cuestión aludida. Asimismo, con nuestra aportación, esperamos haber puesto en valor la producción teatral de José Julián López de Castro, escritor desatendido del Setecientos español. 


\section{BIBLIOGRAFÍA}

Aguilar Piñal, Francisco. Bibliografia de autores españoles del siglo XVIII. Madrid: Consejo Superior de Investigaciones Científicas, II, 1983.

Álvarez de Baena, José Antonio. Hijos de Madrid, ilustres en santidad, dignidades, armas, ciencias y artes. Madrid: Oficina de D. Benito Cano, III, 1790.

Andioc, René. Teatro y sociedad en el Madrid del siglo XVIII. Madrid: Castalia, 1987.

Arenas Cruz, María Elena. "Las representaciones de Rojas en el siglo XVIII y su valoración en el Memorial Literario". Francisco de Rojas Zorrilla, poeta dramático, Actas de las XXII Jornadas de Teatro Clásico. Eds. Felipe Blas Pedraza Jiménez, Rafael González Cañal y Elena Marcello. Almagro: Universidad de Castilla-La Mancha, 2000. 379-394.

Balestrino, Graciela. "Calderón y el metateatro: abismación, trampantojo y apoteosis del comediante en Mojiganga del mundinovo". Teatro de palabras. Revista sobre teatro áureo 5 (2011): 119-141.

Barrera y Leirado, Cayetano Alberto de la. Catálogo bibliográfico y biográfico del teatro antiguo español, desde sus orígenes hasta mediados del siglo XVIII. Madrid: Imprenta y Estereotipia de M. Rivadeneyra, 1860.

Bernaldo de Quirós Mateo, José Antonio. El teatro y actividades afines en Ávila (siglos XVII, XVIII y XIX). Madrid: Universidad Nacional de Educación a Distancia, 1994.

Briante Benítez, Federico Juan. "La producción entremesil de José Julián López de Castro". Castilla. Estudios de Literatura 10 (2019): 430-475.

Brioso Santos, Héctor. "Juegos metateatrales y verosimilitud en el teatro del Siglo de Oro: la loa". Similitud y verosimilitud en el teatro del Siglo de Oro. Actas del Coloquio Internacional. Pamplona: Universidad de Pamplona, 2003. 67-88.

Caldera, Ermanno. "Il metateatro di Ramón de la Cruz". Linguistice e Letterature 2 (1977): 81-113.

Canonica, Elvezio. "El teatro dentro del teatro: desde la verosimilitud hasta la identificación en Lo fingido verdadero de Lope de Vega". Similitud y verosimilitud en el teatro del Siglo de Oro. Actas del Coloquio Internacional. Pamplona: Universidad de Pamplona, 2003. 131-148.

Cornejo Vega, Francisco Javier. "Primeros tiempos de la máquina real de los títeres: los actores maquinistas (hacia 1630-1750)". Fantoche 10 (2016): 18-39.

Cotarelo y Mori, Emilio. Colección de entremeses, loas, bailes, jácaras y mojigangas, desde fines del siglo XVI a mediados del XVIII. Madrid: Casa Editorial Bailly-Baillière, 1911.

Cubero Corpas, Carmen. "En torno a La entretenida de Cervantes: el teatro dentro del teatro y el teatro sobre el teatro". El teatro dentro del teatro: Cervantes, Lope, Tirso y Calderón. Coords. José Manuel López de Abiada, Pedro Ramírez Molas e Irene Andres Suárez. Madrid: Verbum, 1997. 59-72.

D’Ors, Miguel. “Autores y actores teatrales en la Pamplona del siglo XVIII". Príncipe de Viana 140-141 (1975): 633-666.

Fernández Gómez, Juan Fernando. Catálogo de entremeses y sainetes del siglo XVIII. Oviedo: Instituto Feijoo de Estudios del siglo XVIII, 1993. 
Fernández Oblanca, Justo. Literatura y sociedad en los entremeses del siglo XVII. Oviedo: Servicio de Publicaciones de la Universidad de Oviedo, 1992.

Forestier, Georges. Le théâtre dans le théâtre sur la scène française du XVII siècle. Genève: Librairie Droz, 1996.

García Valdés, Celsa Carmen. "Carnaval y teatro". Rilce. Revista de Filología Hispánica 13/1 (1997): 25-55.

González Cañal, Rafael. "Cleopatra, una figura femenina del teatro de Rojas”. Actas del Congreso Internacional "Rojas Zorrilla en su IV centenario". Coords. Felipe Blas Pedraza Jiménez, Rafael González Cañal y Elena E. Marcello. Cuenca: Ediciones de la Universidad de Castilla-La Mancha, 2008. 269-292.

Hermenegildo Fernández, Alfredo. "El personaje espectador: teatro en el teatro del siglo XVII". Scriptura 11 (1996): 125-140.

"Mirar en cadena: artificios de la metateatralidad cervantina". Cervantes y la puesta en escena de la sociedad de su tiempo. Actas del Coloquio de Montreal 1997. Coords. Catherine Poupeney Hart, Alfredo Hermenegildo Fernández y César Oliva Olivares. Murcia: Universidad de Murcia, 1999. 77-92.

"Sombras escénicas de la realidad y de la ficción: el teatro de Cervantes". En torno al teatro del Siglo de Oro. Actas de las XV Jornadas de Teatro del Siglo de Oro. Coords. Irene Pardo Molina y Antonio Serrano Agulló. Almería: Instituto de Estudios Almerienses, 2001. 23-38. 211-226.

"Usos de la metateatralidad: las comedias de Lope de Rueda". Scriptura 17 (2002):

et al. "Más allá de la ficción teatral: el metateatro". Teatro de palabras. Revista sobre teatro áureo 5 (2011): 9-16.

Hernández Martín, Alicia. La metateatralidad del teatro breve del siglo de oro. Análisis de loas y entremeses de Agustín de Rojas Villandrando y Francisco de Castro. Valladolid: Universidad de Valladolid, 2016.

Hornby, Richard. Drama, Metadrama and Perception. London / Toronto: Associated University Press, 1986.

Huerta Calvo, Javier. El teatro breve en la Edad de Oro. Madrid: Ediciones del Laberinto, 2001.

Igartúa Landecho, María Emilia. José Julián de Castro: autor popular del siglo XVIII. Madrid: Universidad Complutense de Madrid, 1991.

Julio, María Teresa. "El arte de fingir: juegos metateatrales en Lucrecia y Tarquino de Francisco de Rojas Zorrilla”. Lectura y Signo. Revista de Literatura 2 (2007): 157-174.

López de Castro, José Julián. El gato, s.1., s.i., s.a.

El informe sin forma. Sevilla: Imprenta de Nicolás Vázquez, s.a.

El piscator de las damas o Los cármenes de Granada. Madrid: Imprenta de Francisco Javier García, s.a.

Los áspides de Cleopatra. Madrid: s.i., s.a.

Los médicos a la moda. Manuscrito, s.a. Biblioteca Nacional de España.

Los sastres desastrados. Madrid: Imprenta de Francisco Javier García, s.a.

Un ventero y un ladrón, ¿cuál es mayor? s.1., s.i, s.a. 
El piscator de las damas o La quinta de Manzanares. Madrid: Imprenta de José Francisco Martínez Abad, 1752.

Los indianos de hilo negro. s.1., s.i., 1793.

El castigo de un celoso. s.1., s.i., 1793.

Madroñal, Abraham. "De nuevo sobre la autoría de Los refranes del viejo celoso, entremés atribuido a Quevedo". La Perinola. Revista de Investigación Quevediana 17 (2013): 155-177.

Maestro, Jesús G. "Cervantes y Shakespeare: el nacimiento de la literatura metateatral". Bulletin of Spanish Studies. Hispanic Studies and Research on Spain, Portugal and Latin America 81/ 4-5 (2004): 599-612.

Manero Sorolla, María Pilar. "La configuración imaginística de la dama en la lírica española del Renacimiento. La tradición petrarquista". Boletín de la Biblioteca de Menéndez Pelayo 68 (1992): 5-71.

Martínez López, María José. El entremés, radiografía de un género. Toulouse: Presses Universitaires du Mirail, 1997.

Pérez de León, Vicente. "Sobre la realidad improvisada en el teatro breve del Siglo de Oro". Hispania 87/1 (2004): 13-21.

Ripodas Ardanaz, Daisy. El indiano en el teatro menor español del Setecientos. Madrid: Atlas, 1986.

Sáez Raposo, Francisco. "Del entremés a la comedia: hacia el itinerario de la metateatralidad". Teatro de palabras. Revista sobre teatro áureo 5 (2011): 29-39.

Urzáiz Tortajada, Héctor. Catálogo de autores teatrales del siglo XVII. Madrid: Fundación Universitaria Española I, 2002.

Zugasti Zugasti, Miguel. "Teatro en el teatro (TeT): cuatro ejemplos de Cervantes, Lope, Tirso y Vélez”. Teatro de palabras. Revista sobre teatro áureo 5 (2011): 57-85. 